\title{
9
}

\section{Disconnect to Reconnect! Self- help to Regain an Authentic Sense of Space Through Digital Detoxing}

\author{
Gunn Enli and Trine Syvertsen
}

\section{Introduction}

"Look away from our screens and enter the physical world we are in" (Colier, 2016: loc. 1843), ${ }^{1}$ is a typical call for action in contemporary self-help literature. Like advice to stop smoking, lose weight, and improve homes, advice to do a digital detox is emerging as a popular self-help sub-genre. Drawing on an empirical analysis of 15 self-help books, this chapter explores advice to reconnect with social and physical spaces by taking a break from digital technology. ${ }^{2}$ Digital detox is a relatively new term (Syvertsen, 2020), but as the chapter will show, its ideological foundations are familiar from a long history of media and technology criticism. Research on digital detox and disconnection is proliferating (see, e.g., Aranda \& Baig, 2018; Baumer et al., 2013; Baym et al., 2020; Brennen, 2019; Neves et al., 2015; Schoenebeck, 2014), yet, the phenomenon is rarely placed in a historical context, and its values rarely understood as part of a broader cultural inclination. This chapter analyzes recommendation to detox in the light of classical and contemporary criticisms of media influence.

A defining characteristic of the media is that they change our experience of space and introduce new virtual spaces. From the telegraph to mobile media, new communication technologies have prompted reflection over

1 Some of our sources are e-books without page numbers, marked with "loc."

2 The chapter is part of the project Digitox: Intrusive media, ambivalent users and digital detox, funded by the Norwegian Research Council 2019-23. https://www.hf.uio.no/imk/english/research/projects/digital-disconnection/index.html. 
what it means to be situated in space and have changed the norms for behavior in different spaces (Carey, 2015). A fundamental change is epitomized in Joshua Meyrowitz's famous term "no sense of place," describing how the media "decreased the significance of physical presence in the experience of people and events." As Meyrowitz notes: "One can now be an audience to a social phenomenon without being physically present; one can communicate directly with others without meeting in the same place" (1985: vii).

While the ability of media to transmit sound, images, and text across vast distances fascinated the general public, these characteristics also prompted media resistance. The claims that mass media invade and transform social and physical space and create a false sense of proximity have been central in the critique of telecommunications, broadcasting, and digital media (Syvertsen, 2017). The phenomena of digital detox and intentional disconnection reflect a demand for practical solutions to combat an uncomfortable sense of spatial dislocation and a yearning to return to a more authentic sense of space (Syvertsen \& Enli, 2019). A fundamental premise in texts recommending digital detox is that media disconnect us from real life and that actions are necessary to reconnect. This chapter discusses two aspects of digital detox that are both framed as reconnecting: discourses and measures about social spaces and means to reconnect with physical spaces. Common to both is a presumption that presence here-and-now is essential for an authentic life; and a suspicion that the media are inauthentic and that media-created spaces are less real than physical spaces (Enli, 2015).

There is a long tradition of cultural pessimism toward mass culture, where the media are seen as vehicles of indoctrination and trivialization, turning citizens into passive consumers (Brantlinger, 1983; Syvertsen, 2017). While most contributions emphasize the implications of economic and political structures (see, e.g., Horkheimer \& Adorno, 1997), so-called medium theorists (Meyrowitz, 1994) focus on the nature of the medium as a cause of social change. "The medium theorists do not suggest that the means of communication wholly shape culture and personality, but they argue that changes in communication patterns are one very important contribution to social change and one that has generally been overlooked" (Meyrowitz, 1985: 18). While self-help literature rarely includes historical references (apart from pointing to a vague "before" when things were better), its discourse ties in with a medium-theoretical historical tradition; 
in a sense it turns traditional criticisms of the media into motivational narratives for a better life.

Following the literature review, we turn to digital detox and the chapter's empirical material. Although a digital detox is often defined as a temporary pause from digital media, the term is used to describe a range of activities including offline periods, time management, screen-free zones, the deletion of apps and platforms, muting and blocking, and transferring to light or analog devices (Syvertsen, 2020). Since digital detox is often framed as an exercise of willpower, self-help books, sites, and social media accounts proliferate (Jorge, 2019; Karlsen \& Syvertsen, 2016; Syvertsen \& Enli, 2019). Hence, self-help books are useful sources of insight into how spatial invasion is conceptualized and handled in popular discourse, and how the authors of these books address their implied readers.

The empirical analysis is presented in three parts structured by this overarching research question: How are social and physical reconnection conceptualized in popular discourses about digital detox, and what characterizes the motivational discourses urging users to regain a more authentic sense of space? The first and second analyses are on social and physical disconnection, while the third illustrates how (partial) disconnection is employed as a vehicle of fundamental life change. In contrast to arguments that traveling and relocation are vital to a new outlook, the digital detox literature is about changing lives while staying in the same place; it is the reduction of digital connections that leads to a more authentic sense of space.

\section{Theoretical Perspectives-Media and Space Dislocation}

The relationship between media and space is a central topic in media theory and history (Carey, 2015; Couldry \& McCarthy, 2004). While writing and printing overcame space limitations, the telegraph revolutionized communication through synchronous transmission, and wireless telephony and telegraphy intensified the experience of change. "As broadcasting, radio gave uniformity to a diverse population, contact to the lonely and comfort to scattered listeners," says Fang (2015: 225). However, it also "created a landscape that depended on unseen others for information and entertainment" 
(p. 225); a fact that prompted criticism that broadcasting spaces were inauthentic and undermined the connection to "real space."

Within "medium theory," McLuhan (1968 [1964]) and Postman (2005 [1985]) are often cited as opposites: the first more optimistic than the second in regard to how they view the technology (see, e.g., Croteau \& Hoynes, 2019). In this chapter, we focus on two critics with a starker and darker view, the German philosopher Günther Anders (1956) and US activist Jerry Mander (1978 [1977]), before turning to contemporary critics of digital media. In other books, the authors have provided broad historical reviews of media-critical works (Enli, 2015; Syvertsen, 2017); here we have chosen to accentuate some less familiar contributions to illustrate the breadth of the literary tradition. Anders and Mander are generically similar, both direct their appeals at the general public, and both combine sweeping generalizations with rich examples and details, not unlike the narrative style in some contemporary self-help books. As social manifestos, both Anders and Mander crystallized their message in distinct theses-10 and 4 respectively-on how broadcasting undermined humanity and society. Nevertheless, they stand as representatives of a broader canon that also include human geography literature such as Edward Relph's Place and Placelessness, an influential 1976 contribution arguing that mass communications and mass culture undermined an authentic sense of place (Seamon \& Sowers, 2008).

A common starting point in the medium-theoretical literature is the rejection of the notion of neutral technology, as Mander explains in Four Arguments for the Elimination of Television (1978 [1977]: 43):

Most Americans, whether on the political left, center or right, will argue that technology is neutral, that any technology is merely a benign instrument ... It will be the central argument of this book that these assumptions about television, as about other technologies, are totally wrong.

Similarly, in The World as Phantom and Matrix [English title] (1956), Anders argues that broadcasting technologies could not be perceived as means; instead, they were ends in themselves with a commanding presence locking people into a pseudo-reality. Media historians Bastiansen and Dahl (2003: 380) describe how Anders's criticism prompted debate when it was published in Norway in 1965 with the Norwegian title A false world [En falsk 
verden]; despite its dark pessimism, they note, it had "surprisingly sharp observations."

Both Anders and Mander are concerned with how media disconnect people from social and physical spaces. Anders is particularly detailed on the undermining of social space; he called television "a negative family table" and argued that the home was demoted to a "container" for the video screen. Television had not become the center of family life but rather "a common avenue of escape for the members of the family":

In fact, the family members are not seated in such a way as to face one another; the arrangement of chairs in front of the television screen is a chance affair and should the family members look at each other it is only by accident, just as any speech between them (if they should ever want or be able to talk) is a result of chance. They are no longer together, but merely placed one next to the other; they are mere spectators. In these circumstances one can no longer speak of weaving the fabric of family life, or of a world in which they participate or which they create together. What takes place instead is only that the members of the family fly towards a realm of unreality at the same time, all of them together in the best cases, but never really share the experience at the point of liftoff ... (Anders, 1956: 16-17)

According to Anders, television undermined the home as a social space and placed family members in a "realm of unreality" where they were "soloists of mass consumption" (p. 17). Anders also formulated a lost connection to physical reality in his 10 theses on the revolutionary impact of broadcasting, including " 2 . When the world comes to us only as an image, it is half-present and half-absent, in other words, it is like a phantom," and " 8 . When the actual event is socially important only in its reproduced form, i.e., as a spectacle, the difference between being and appearance, between reality and image of reality, is abolished."

Jerry Mander's (1978[1977]) anti-television manifesto grew out of his experience as advertising executive turned political activist. "Without our gaining control over technology, all notions of democracy are a farce," he argued (p. 352), claiming that television led to "a new muddiness of mind" (p. 25) which in turn would facilitate authoritarian society. A crucial tenet was that people could not separate images directly experienced from those 
"which had been processed and altered, and which arrives out of context" (p. 25). The new environment was nothing more than "a stage set or a series of false fronts" (p. 87), he argued, and television locked people into artificial environments with no connection to nature:

Natural environments have largely given way to human-created environments. What we see, hear, touch, taste, smell, feel and understand about the world has been processed for us. Our experiences of the world can no longer be called direct, or primary. They are secondary, mediated experiences. (Mander, 1978[1977]: 55)

Mander presents eight conditions for "the Flowering of Autocracy" (pp. 9798) similar to Anders's principles. One is the elimination of personal knowledge and direct experiences which made it "impossible for the human to separate natural from artificial, real from unreal." Another was to separate people from each other: "When people gather together, be sure it is for a prearranged experience that occupies all their attention at once" (p. 98). Chapter XII called "The replacement of human images by television" describes how images from distant spaces take over people's minds and disconnect them from the here-and-now:

When you are watching TV, you are not daydreaming, or reading, or looking out the window at the world. You have opened your mind, and someone else's daydreams have entered. The images come from distant places you have never been, depict events you can never experience, and are sent by people you don't know and have never met. Once their images are inside you, they imprint on your memory. They become yours. (Mander, 1978[1977]: 240).

Anders and Mander both use apocalyptic vocabularies resembling literary warnings emerging in the same decades, such as Brave New World (Huxley, 2006 [1932]), 1984 (Orwell, 2008 [1949]), and Fahrenheit 451 (Bradbury, 2013 [1953]). On one level, all these are stories of how media and mass culture invade private space, destroy solidarity and filial bonds, and lock people into serfdom and slavery. To the degree that hope is expressed in these books, it through escaping screens and modern mass culture and reconnecting with non-mediated spaces and cultures (Syvertsen, 2017). 
Although the tone is lighter and the positive contributions of technology are acknowledged, contemporary criticism of space dislocation caused by digital media draws on classical narratives. From the canon of books criticizing digital media, we have selected Sherry Turkle (2011, 2015) for her sharp criticism of social space dislocation, and Richard Louv (2008 [2005]) for the arguments about disconnection from natural spaces.

With Alone Together (2011) and Reclaiming Conversations: The Power of Talk in the Digital Age (2015), Sherry Turkle addresses the preference of "machine-mediated relationships" (2011:11) and comments on occasions where people fly far only to be preoccupied with their technologies, i.e. "alone together." Hence, she ties in with Anders's concept of "soloists of mass consumption" although she talks about digital media and not broadcasting. She uses the bubble metaphor to describe what she sees as an inauthentic space created with technology: "Life in the media bubble has come to seem natural" (p. 16). Virtual worlds draw people away from time with family or friends, "sitting around, playing Scrabble face-toface, taking a walk, watching a movie together in the old-fashioned way" (p. 12). The real world becomes a disappointing place:

Not surprisingly, people report feeling let down when they move from the virtual to the real world. It is not uncommon to see people fidget with their smartphones, looking for virtual places where they might once again be more. (Turkle, 2011: 12).

As a psychologist, Turkle is concerned with technology as a separating force for human interaction; she places "high value on relationships of intimacy and authenticity" (2011: 6). Her second book on the topic (2015) discusses the importance of conversations for society, democracy, workplaces, and social glue. Not least in families, conversation "is a space to be authentic" (p. 106). Face to face, we develop the capacity for empathy:

This new mediated life has gotten us into trouble. Face-to-face conversation is the most human-and humanizing-thing we do. Fully present to one another, we learn to listen. It's where we develop the capacity for empathy. It's where we experience the joy of being heard, of being understood. (Turkle, 2015: 3). 


\section{Rethinking Disconnection}

Turkle is adamant that her argument "is not anti-technology," but "proconversation" and that phone checking and web-surfing take us away from where we are. "We miss out on necessary conversations when we divide our attention between the people we're with and the world on our phones," she argues, and we "go to our phones instead of claiming a quiet moment for ourselves." Like Mander, she reflects on how dreams are affected: "We have convinced ourselves that surfing the web is the same as daydreaming. That it provides the same space for self-reflection. It doesn't' (Turkle, 2015: 25).

Turkle draws on a similar vocabulary to Mander and Anders, but the emphasis is more on "us" than on the media. We are not victims of autocratic, one-dimensional systems; instead, "we" are willing accomplices using digital media to undermine our presence here and now. Similarly, contemporary critics of alienation from nature portray "us" as willing contributors. In the 2005 bestseller Last Child in the Woods, Louv (2008 [2005]) introduces the term "nature-deficiency disorder" to describe a growing gap between children and nature. Louv argued that well-meaning schools, poor urban planning, fearful parents, and electronic communication keep children away from green spaces, essential for recuperation, presence, and ecological consciousness. A later book, The Nature Principle (Louv, 2012) discusses nature deficiency for adults and the need to reconnect, hence the subtitle: Reconnecting with Life in a Virtual Age.

Louv (2012: 3) describes his book as "[p]rimarily a statement of philosophy," yet refers to a growing body of theoretical, empirical, and anecdotal evidence describing the restorative power of nature: "its impact on our senses and intelligence; on our physical, psychological, and spiritual health; and on the bonds of family, friendship, and the multi-species community." To "balance the virtual with the real" (p. 4), he argues, is essential to overcome phenomena such as "place blindness" (p. 100). In the social manifesto tradition, he introduces "Seven overlapping precepts" on how "the transformative powers of nature, can reshape our lives now and in the future" (p. 5). The first and most essential principle is "The more high-tech our lives become, the more nature we need to achieve natural balance." He is optimistic, "not only can nature-deficit disorder be reversed, but our lives can be vastly enriched through our relationship with nature, beginning with our senses" (p. 11):

Taken to its extreme, a denatured life is a dehumanized life.... There's no denying the benefits of the Internet. But electronic//immersion, without 
a force to balance it, creates the hole in the boat-draining our ability to pay attention, to think clearly, to be productive and creative. The best antidote to negative electronic information immersion will be an increase in the amount of natural information we receive. (Louv, 2012: 23-24)

Like other contemporary critics, Louv takes care to show that he is not "against" digital media. Yet, he quotes a naturalist using the disconnectingreconnecting metaphor: "Connecting dots. It's as simple as that. Off the Internet, everything is connecting you with the world. Everything" (p. 25).

\section{Material and Analysis}

Digital detox is often framed within a self-help context, and shares traits with other self-help trends such as time management, voluntary simplicity, decluttering, and mindfulness (Syvertsen, 2020) (see also Hesselberth, this volume). Hence, self-help books offer insights on how problems with invasive technology are framed, and this chapter analyzes 15 books within the genre (Bratsberg \& Moen, 2015; Colier, 2016; Dalton, 2019; Ellis, 2017; Formica, 2015; Goodin, 2018; Huffington, 2015; Krupp, 2014; Price, 2018; Schara, 2017; Shlain, 2019; Snow, 2017; Talks, 2013; Tennant, 2012; Zahariades, 2016). ${ }^{3}$ While some are memoirs, describing profound life changes, others are short manuals; yet all include the familiar characteristics of the genre such as personal experiences, inspirational quotes, and advice for self-regulation (Liang, 2015; McGee, 2005). The books are selected to get a manageable sample with some internal variation in terms of length, format, national origin of the author, and year of publication (from 2012 to 2019). Yet, the analyzed corpus is fairly homogenous in style and content. The implied reader is a person who experiences digital media as invasive, but is reluctant to take action, because of imagined difficulties living without constant online connection. Typically, the implied reader is not overtly critical of the technology, but self-critical: in demand of practical ways to deal with problems.

3 Some of the books have also been discussed in other publications, but this chapter draws on many new sources (Syvertsen, 2020; Syvertsen \& Enli, 2019). Translations from Bratsberg and Moen are ours. 
The books are subject to a thematic analysis where we elicit statements about social and physical space and relate these to cultural criticism of mass and digital media. Drawing on studies of how problems are framed by social movement activists (Benford \& Snow, 2000: 615), each analysis describes three core tasks that authors engage in: Diagnostic_defining the problem and pointing to a cause; prognostic-proposing solutions and outlining a plan; and motivational-creating compelling narratives to motivate action. Through these framing tasks, those recommending a digital detox draw on cultural narratives about invasive technology and turn them into motivational tales of how to regain presence and a more authentic life.

\section{Reconnecting to Social Space}

A social space is usually understood as an area — real or virtual—designed for social interaction. ${ }^{4}$ In this analysis, we are concerned with the spaces where we socialize with others face to face. A century of criticism has pointed the finger at the media for disturbing face-to-face connections and alienating people from close relations. While television was criticized for redirecting viewers' attention away from social interaction, social media is criticized for creating a competition between two social spaces, yet, the implication is in both cases that meaningful relations with people in physical proximity are undermined. In this part, we discuss how the problems with social spaces are diagnosed, which actions are suggested, and how narratives are designed to motivate action.

The self-help literature starts from the premise that the dire predictions of intrusive media have come true. Technology is blamed implicitly, if at all. Instead, the problems are diagnosed as arising from "our" complicity: "We" allow devices to direct us away from our nearest and dearest. As argued in Off: Your Digital Detox for a Better Life: "Every day we reject an experience or a relationship in favor of time with our screens" (Goodin, 2018: 111). Goodin continues: "Our loved ones feel ignored and resentful that our phones and screens get to spend more time with us than they do." In Log Off (Bratsberg \& Moen, 2015: 39), the sense of rejection is described as jealousy:

\footnotetext{
${ }^{4}$ https://www.lexico.com/definition/social_space.
} 
Screen jealousy is a new term describing how heavy use of mobile phone or tablet can harm a relationship. It's possible to develop jealousy in relation to a screen. Who do you love the most? Who are you chatting with? Who are commenting? Likes and hearts. Are you cheating?

In another book titled Log Off, with the subtitle: How to Stay Connected after Disconnecting, Snow (2017: 61), suggests a psychological diagnosis: "Why do we behave like this? Because we're unwilling or uncomfortable confronting our own feelings now, especially loneliness." However, societal changes are also listed as causes. In The Power of Off: The Mindful Way to Stay Sane in a Virtual World (Colier, 2016: loc. 1159), Colier argues that the media have broken down the barriers between public and private:

As a society we have lost the distinction between public and private space. It used to be that if you were at home with your family or out on a date or some other such personal encounter, you were not available to everyone else. The setting aside of times and places where the outside world was not allowed, special places just for special people in our lives, added the sense of importance to those relationships. Now, always powered on and available to the public through our devices, always relating with the public through social media, many of us have stopped granting special importance to those in our private world. The public is now just as important as the private.

This quote points to context collapses and etiquette collisions in digital media (Carey, 2015). But there is also a deeper strand of thought here, alluding to the notions advocated by Anders, Mander, and Turkle that the media are vehicles to break intimate bonds, leading people to voluntarily isolation. While media appear to bring people together, the books are based on the premise that they draw us apart. According to Goodin (2018: 98):

Humans are social animals and we crave connection. With all of your many online friends, fans, and followers, it might seem like we have more connections than ever before. And yet, why do we feel isolated at times?

Günther Anders argued that broadcasting undermined the home as a social space and placed family members in a "realm of unreality," whereas Jerry 


\section{Rethinking Disconnection}

Mander saw the television environment as "a series of false fronts." Similarly, in several of the self-help books, the spaces for socialization created by digital media are perceived to be inauthentic. In Unfriend Yourself: Three Days to Discern, Detox and Decide about Social Media, Tennant (2012: 52) downgrades online communities:

Online community-an oxymoron really-.. It's just not as good as the real thing and leaves a gross aftertaste (similar drinking Diet Coke). At the end of the day, there is no replacement for the real thing in-the-flesh togetherness.

A similar argument comes from Huffington (2015: 62) in Thrive: The Third Metric to Redefining Success and Creating a Happier Life:

The connection that comes from technology is often an unfulfilling, ersatz version of connections. Its siren call (or beep or blinking light) can crowd out the time and energy we have for real human connection.

Following diagnostics, the prognostic framing task is to design solutions to the problem: how to reconnect to the intimate space with your nearest and dearest. The keywords in the titles ("off" and "log off" in different combinations) say it all: The most important is to make a conscious choice to disconnect, at least partially, from the technology and prioritize face to face. "Do something with real people. Hopefully this is self-explanatory," says Price (2018: 142). "Be present. Don't split your attention with a screen," Goodin (2018: 111) echoes. Tennant (2012: 63) elaborates:

Instead of allowing our relationships to be mediated, we have to choose to be face to face more often than not. This means going for coffee, playing a game, and using our words to move past communication and arrive at communion.

The argument echoes Turkle's (2011: 12) description of the value of "sitting around, playing Scrabble face-to-face, taking a walk, watching a movie together in the old-fashioned way." However, the self-help books recognize that it is not easy to make these choices and that practical advice is necessary. First and foremost, they recommend clearing intimate spaces of technology. 
Martin Talks (2013: 85) is one of several commending: "Ban phones from the bedroom." In Cellphone Addiction: Freedom from Social Media, Texting and Online Video, Krupp (2014: loc. 260) recommends phone-free zones and unplugging during vacations:

Maintain Phone Free Zones: No using social media, playing game or texting while you are in the bedroom. It is very important to dedicate your spaces and time from your telecom freedom and meet a wide range of people. Make it also a habit not to check your cell phone repeatedly for new messages and missed calls every couple of minutes. If your life is designed on being connected, this is the time to make unplugging a part of yourvacation.

In the cultural criticism reviewed, media technology was described as something of a Trojan horse. Self-help books recognize that guests may bring unwelcome devices to the house and suggest defense measures at the gate. In How to Break Up With Your Phone, Price (2018: 124) recommends a phone basket: "When you have guests over to your home, consider asking them to leave their phones in a basket by the door." Like Krupp, he also recommends not to pick up the phone when with others "First step: consider doing not responding. (What's the worst that could happen?)" (p. 127).

The motivational narratives concerning social space promise that steps such as these will lead to more authentic connections, "[r]eal relations happening in real life" (Bratsberg \& Moen, 2015: 144). "The sound of our laughter in the flesh was so much better than it was over Skype. It was that moment that I realized how very necessary face-to-face relationships are," says Tennant (2012: 51-52). A central argument in the motivational narratives is also that being together in the flesh, rather than being distracted by online communication, is necessary for "empathy, love and compassion" (Bratsberg \& Moen, 2015: 40). In Digital Detox: Unplug to Reclaim Your Life, Zahariades (2016: 74) also creates a motivational narrative similar to the arguments of Turkle, and the conversations breed empathy:

When you put aside your phone and other devices, you'll develop a heightened sense of empathy. You'll be better able to read people's faces and body language and recognize the emotions they're experiencing. 
The aim is to return to a stage of being "authentically present in conversations with friends and family" (Bratsberg \& Moen, 2015: 140). Connecting face to face will combat the sense of isolation and create deeper connections, according to Zahariades (2016: 75):

You'll feel more connected to others. You'll be able to give people the attention they deserve. In return, you'll receive more attention yourself. Forming such connections can be a deeply rewarding experience.

The motivational narratives recognize that the project is not without risks. Tennant (2012: 64) notes: "Being honest is hard, being authentic is sometimes terrifying, and relating in the flesh is risky." However, he continues, "when we take a risk and engage in communication, we find life's simplest and profoundest pleasure: joy." In this quote, the implied reader is evident as a "we," a person identifying with and sharing experiences with not only the author but an undefined community of readers or even a movement searching for authentic connections.

To summarize, the self-help narratives start from the premise that technologies have invaded social space, drawing on familiar elements from cultural criticism of the media. Contrary to the perception that mass and digital media connect people, the self-help books, and cultural critics, see them as disconnectors; hence reconnection is the way forward. As Goodin (2018: 98) notes: "We need to disconnect from superficial online relationships, and reconnect with those that matter in the real world." To Huffington (2015: 250), this means leaving "the bubble" (a metaphor used by Turkle), both in a social and physical sense:

Technology has made it possible for us to live in a self-contained, disconnected bubble twenty-four hours a day, even while walking down the street listening to music on our smartphones. Our devices might seem like they're also disconnecting us from the world around us. And without being connected to the people we encounter, it's hard to activate our hardwired instinct for empathy.

Other contributions also draw together arguments concerning social and physical spaces, bringing us to the next level of analysis. Typical, fundamental questions about social and physical presence are linked, such as in 
Colier (2016: loc. 1843): "Do we want to give up our collective and connected societal space and shared experience of life that includes other people in our physical world?"

\section{Reconnecting to Physical Space}

While a social space can be understood as an area for social interaction, perspectives concerning physical space pertain to interaction with elements in the physical environment. A typical trait of modern media is the "doubling of places," a term suggested by Scannell (1996) to describe how audiences are present in two places at the same time, for example, in their living room and at a football stadium. As noted, critics have been skeptical of the media's ability to draw people's attention away from where they are, inserting a layer between them and their physical surroundings. This part discusses how the problems with physical space are diagnosed, which actions are suggested, and how narratives are designed to motivate action.

Like arguments about social spaces, a key argument is that "we" have lost the ability to be present where we are. Intrusive media are presented as a fact, leaving "us" in a situation where "we" are not mindful and do not notice our surroundings. In The Joy of Missing Out: Live More by Doing Less, Dalton (2019: loc. 2619) argues that:

we are often so focused on our screens we forget to look around. We forget to interact with the world around us, we don't look up; we walk, eyes down hunched over our phones like addicts. We lost the ability to connect. Connect with others and ourselves.

The premise is that loss of connection to the physical environment leads to disconnection from others and ourselves. The books have plenty of anecdotes telling how authors have been to places where they did not pay attention, and instead staged their experiences through social media, as in Bratsberg and Moen (2015: 23):

One summer, I checked in on so many apps that none of my friends needed to ask what we had done and how we had been. I had shared every 


\section{Rethinking Disconnection}

centimetre of that vacation. But what did I remember? Nothing. I had not been present in the real vacation. Extremely sad.

The decoupling of the "real vacation" from the "staged" version is parallel to Mander's perspective about the television environment as a "stage set"; only with social media, it is the users themselves who transform their environments. The self-help books lack Mander's path to autocracy but resemble his and Louv's arguments about the dangers of being disconnected from nature. In Digital Detox: 7 Steps to Find Your Inner Balance (Formica, 2015: loc. 198), Formica details the argument:

Most of us live in urban environments and have gradually disconnected from nature. You see, humans have lived on earth for at least 200,000 years, always in contact and in symbiosis with nature. The disconnect that we are experiencing now from nature is likely to have significant and unprecedented consequences on our inner balance.

Reflecting the dual nature of the problem, the remedies suggested are both about a general reconnection to physical space and measures to bring us closer to nature. The primary advice is to "look away from our screens and enter the physical world we are in" (Colier, 2016: loc. 1843). A series of pursuits are suggested to overcome "place blindness" - to use Louv's termincluding art, creativity, culture, and travel. "If you really want to capture a moment; to immerse yourself in a place; to record your true response to a situation; then art is a great way," says Talks (2013: 7). In A to Z of Digital Detoxing: A Practical Family Guide, Zahariades (2016: 138) echoes: "If you've been wanting to visit a particular locale, whether it's the beach, a new museum, or a swanky jazz club, now is the time to do it." Huffington (2015: 178) also recommends museums as places to reconnect:

Museums and galleries remain among the few oases that can deliver what has become increasingly rare in the world. The opportunity to disconnect from our hyperconnected lives and experience the feeling of wonder.

Several authors refer to the need to allow for more surprise and spontaneity to combat the alienating impact of media engagement. "Walk on a line. Surf a wave. Yoga. Summit walks. Mountain hiking. Mountain climbing" are some 
of the (upmarket) suggestions from Bratsberg and Moen (2015: 136): “These activities require 100 percent presence." Price (2018: 141) is more down to earth; according to him, separating from your phone "is a perfect opportunity to allow serendipity to re-enter your life":

Take a walk in a new neighbourhood. Try a restaurant you've been curious about. Look at the listings in your local paper and go to something new. No matter what you do, it's likely to be more memorable than staring at your phone.

Besides, there is much advice on reconnecting with nature, as Goodin (2018: 54) argues:

Reconnecting with nature is one of the very best things to make time for each day. Keeping one foot always in the digital world means we're losing our valuable connection with the natural world.

Talks (2013: 67) is one of several who recommend gardening as "a good antidote to our fast technology world." Gardening is "good for the mind, body and soul," and the advice is this: "Go and buy some seeds and plant them." Much of the literature also recommends activities that combine mindfulness with reconnecting to nature, as in this quote:

Stop, Breathe and Be is just what is sounds like: you stop what you are doing, take a slow, deep breath, and tune in to the details of what you're experiencing in that moment. There are many ways to do thus, from noticing the physical sensations in your body to scanning your thoughts and emotions to taking note of your surroundings. (Price, 2018: 128)

The narratives place a strong emphasis on mental exercises to combat the sense of spatial dislocation presumably induced by digital media. In motivational narratives, the emphasis on personal rewards is stressed: a life with less restlessness, and one that is calmer and more meaningful. "When invited to be in just one place at one time, just here, we experience a sense of calm," as argued by Colier (2016: loc. 418). Adherents can also expect to become more creative: "Stillness also gives your mind the space it needs to be creative and come up with ideas," says Price (2018: 129). Zahariades (2016: 165) echoes: 


\section{Rethinking Disconnection}

Don't be surprised if your newfound creativity leads to a greater sense of personal fulfilment. It's a natural effect of quarantining yourself from the onslaught of digital media.

While scientific references are anecdotal and sparse in many self-help books, Formica (2015: loc. 210) alludes to the ideas of nature deficiency and uses science to motivate:

Recently, it has been scientifically demonstrated that having direct contact with the earth has a healing power.... It is particularly important to be in direct contact with dirt, grass, sand, or any type of soil, daily.

To summarize, the self-help books recommend breaks from digital media also as a measure to combat a sense of physical dislocation. Instead of seeing the ability to be "two places at once" as an advantage (Scannell, 1996), it is seen as detrimental to physical and mental health. The recommendations concerning physical space also emphasize what individuals can do, without dwelling on the faults of the technology. Again, the recipe is partial or temporary disconnection as a way of reconnecting; to immerse oneself in nature and engage in the physical surroundings is rewarding both in a physical and social sense:

When we join the physical world, we notice the other people with whom we share our space and our planet and with whom we might share a smile, a conversation, or a frustration. (Colier, 2016: loc 1869)

\section{Reconnecting: Dramatic Awakening and a More Authentic Life}

Although the literature is homogenous, a distinction can be drawn between self-help books that are manuals and those more akin to memoirs. The border between the two is blurred, nevertheless, in this final analysis we use three memoir-type contributions (Ellis, 2017; Schara, 2017; Shlain, 2019) to illustrate how (partial) disconnection is depicted as a vehicle of fundamental life change. The memoirs illustrate how the narratives on social and physical space are connected and how disconnecting is infused with transformative qualities. 
There are many descriptions of how a move to a new physical space can be life changing. In the tradition of Thoreau's 1854 classic Walden, traveling to distant places or shifting to a simpler life in nature is a road to wisdom. Contemporary phenomena such as the Australian "seachange" (Osbaldiston, 2012) describe how individuals abandon life in the city and migrate to rural coastal communities to achieve a more "authentic sociability" (p. 32). For sea-changers, authenticity is the place; the surrounding nature, culture or community need to have a certain aesthetic or charm (p. 130). Although the books about digital detoxing share with sea-changers the belief that "we" need to "tune in" to our "internal voice" (p. 141), the arguments in digital detox memoirs are not about relocating to a new place. Instead, disconnection from technology is a method to reconnect with people and the place where you are.

Digitox: How to Find a Healthy Balance for Your Family's Digital diet, is Mark Ellis's report on a three-year family experiment of limiting the use of technology (2017). The author portrays himself as an Internet addict, a semi-reformed "technoholic." Consistent with the genre, the narrative describes a dramatic awakening as a starting point and a motive for the lifestyle turnaround. The awakening came in the form of a memory of an alternative space; a recollection of a cabin where he had experienced mental peace. He realized that he was far away from that peaceful image in his current life: "One Sunday morning three years ago, it dawned to me that we were as far as humanly possible from our log cabin. Conversation had been lost, but the house was far from silent." What later turned into a permanent change in lifestyle, started with a "moment":

I had a moment,--failing to resolve the arguments around me (which were disturbing my own gadget enjoyment) I switched it all off. Everythingthe TV, the gaming, the router, and announced that the day was going to be spent without the gadgets. (Ellis, 2017: loc. 1015).

While Ellis first thought of the switch-off as punishment, it was the start of a more genuine and authentic connection to others and the surroundings. The family implemented "Tech Free Sundays" and rules clearing social and physical spaces: no phones in bedrooms and at the table, and screen-free evenings. The book talks to an implied reader who is keen to experience a deeper life change, or at least "see how it feels to break down the addiction chains, 


\section{Rethinking Disconnection}

then take a step back and gain a slightly different perspective on your behaviour and that of your family" (p. 166). Instead of being a purely individualistic endeavor, the proposals address an implied community of parents and caregivers with responsibilities beyond self.

An Analog Month: A Digital Detox in the Real World (Schara, 2017) is a diary of the author's digital media break. Like Ellis, Schara describes how she was a phone addict with 50 to 60 apps on her phone and how she transformed her life long-term. Although friends and coworkers reacted and expressed concern, Schara avoided temptation and became used to the new lifestyle; she describes day 16 at the "best day yet," and by day 27 she writes that "being without internet or apps is no longer hard" (loc. 420). Although the new lifestyle is described as cumbersome in some respects, Schara writes that she was amply rewarded. Her motivational narrative centers on how her life improved in major ways; she regained lost time, became less anxious and depressed, more secure of herself, and happier than ever. The key point was that being without the "leash" of a smartphone, she was able to be "fully present in her own life" (loc. 312). Although not physically bound by the smartphone, the connection is described with a metaphor implying inability to move freely both physically and mentally; hence this is a narrative of one woman's liberation struggle.

In 24/6 The Power of Unplugging One Day a Week, Tiffany Shlain (2019) tells of another dramatic awakening. The feeling that she was not paying enough attention to her loved ones physically present was exacerbated by the death of her father, and the birth of her daughter, only days apart. Of the time with her father she writes:

During the period when he was dying, there were times when he had only one lucid hour a day. When I went to visit him, I turned my phone off completely. I needed to protect the time and space around us to focus on him and the moments we had left. (Schlain, 2019:3)

Shlain and her husband introduced a "Tech Sabbath"-one day a week without devices in order to "have more authentic connections with one another without screens" (p. 10). The benefits were better social connection, more eye contact and attention, as well as inner peace and patience. Shlain argues that "eye contact is the first and last form of communication we have. It's fundamental" (p. 94). The motivational narrative in this memoir also 
focuses on stillness; the author writes on how she found the library to be a "my perfect palace in space": "The silence of that vast space lets you think and feel, imagine and hear" (p. 131). Being in nature is also described as essential for connection (p. 141):

When my family started keeping Tech Sabbaths, it made perfect sense that we'd incorporate nature into the practice.... We try to make being in nature a regular part of our screen-free day.

The implied reader in this case is an unsettled person yearning for inner peace and deeper connections. Like the others, Shlain's story portrays a lifestyle where the alienating forces of technology can be controlled and kept in check. Although the books are based on descriptions of invasive media akin to those found in philosophical, political, and psychological accounts, the personal experiences of the authors indicate that it can all be reversed. As Shlain's experience with being in nature is described:

Being outside makes me feel more attuned and linked to the natural world. Which in turn links me to the world as a whole. It's sort of ironicby disconnecting from screens, I feel more connected to everything and everyone. (Schlain, 2019: 142)

\section{Conclusion}

A fundamental premise in texts recommending digital detox is that media serve as disconnectors and that actions are necessary to reconnect. This chapter has discussed two aspects of digital detox that are both framed as reconnecting: discourses and measures about social spaces, and means to reconnect with physical spaces. Through a thematic analysis of 15 self-help books, we have addressed the following research question: How are social and physical reconnection conceptualized in popular discourses about digital detox, and what characterizes the motivational discourses urging users to regain a more authentic sense of space?

The analysis started with a review of four contributions addressing classical themes in media criticism and resistance, such as the presumed 


\section{Rethinking Disconnection}

undermining of family bonds, escapism, disconnection from nature, and a sense of unreality brought on by media. The metaphor of "bubble" epitomizes the conditions described; a layer has been inserted between individuals, their nearest and dearest, and the physical environs. The implications spelled out for humans is alienation, stress, isolation, as well as a loss of empathy, intimacy, and authenticity. The chapter has further shown how authors of self-help books handle these problems and challenge dominant narratives about the benefits of being online. The analyses have described how authors diagnose the problem, prescribe recipes for action, and create compelling stories motivating people to act. Through these framing methods, those recommending a digital detox draw on cultural narratives about invasive technology and turn them into motivational tales of how to regain presence and a more authentic life.

Regarding how social and physical reconnection is conceptualized in popular discourses about digital detox, the self-help books start from the assumption that dire predictions about technology and social change have come true. Media have invaded us and changed our relationship with social and physical space. Still, the self-help books do not share the dystopic tone of early media criticism. Instead, they describe the main problem as "our" complicity and the fact that "we" let ourselves be led astray by technology. Hence, when suggesting recipes for action, they focus on what "we" can do: Prioritize face-to-face relationships and pay more attention to the physical world.

This promise of authentic connections by reducing one's use of digital media might be criticized for ignoring the fact that also pre-Internet societies have been characterized as inauthentic and failing to create real communities (Riesman, 1950; Sennett, 1970). The idea of more authentic places in a world without Internet and mobile phones might be an illusion, based on a nostalgic ideology and a vague idea about technology as a hindrance for real and authentic connections. Moreover, the focus on individual efforts and self-regulation might be interpreted as "organized self-realization" (Honneth, 2004) and problematized as a path toward feelings of emptiness and depression (Ehrenberg, 1998). Indeed, the books analyzed point to individual struggles of how to cope with social demands and how to improve the self in the area of digital media usage, but also construct a "we" in order to create a perceived community around the individualistic self-improvement project. 
Although the books illuminate many obstacles and difficulties in connection with a technological renegotiation, they hold onto the basic idea that problems can be solved, social and physical dislocation, reversed, and the alienating forces of technology, controlled and kept in check.

\section{References}

Anders, G. (1956). The world as phantom and as matrix. Dissent, 3(1), 14-24. Retrieved from http://marcuse.faculty.history.ucsb.edu/projects/anders/Anders1 956DissentWorldPhantomAndMatrixOCR.pdf.

Aranda, J., \& Baig, S. (2018). Toward "JOMO": The joy of missing out and the freedom of disconnecting. MobileHCI '18: Proceedings of the 20th International Conference on Human-Computer Interaction with Mobile Devices and Services, 18. doi:https://doi.org/10.1145/3229434.3229468.

Bastiansen, H., \& Dahl, H. F. (2003). Norsk Mediehistorie. Oslo: Universitetsforlaget.

Baumer, E. P. S., Adams, P., Khovanskaya, V. D., Liao, T. C., Smith, M. E., Sosik, V. S., \& Williams, K. (2013). Limiting, leaving, and (re)lapsing: An exploration of Facebook non-use practices and experiences. Paper presented at the SIGCHI Conference on Human Factors in Computing Systems, Paris, France.

Baym, N. K., Wagman, K. B., \& Persaud, C. J. (2020). Mindfully scrolling: Rethinking Facebook after time deactivated. Social Media + Society, 6(2), 2056305120919105. doi:10.1177/2056305120919105.

Benford, R. D., \& Snow, D. A. (2000). Framing processes and social movements: An overview and assessment. Annual Review of Sociology, 26, 611-639.

Bradbury, R. (2013 [1953]). Fahrenheit 451. New York: Simon and Schuster.

Brantlinger, P. (1983). Bread and Circuses: Theories of Mass Culture as Social Decay. Ithaca, NY: Cornell University Press.

Bratsberg, L., \& Moen, T. (2015). Logg av. Oslo: Cappelen Damm.

Brennen, B. (2019). Opting Out of Digital Media. London: Routledge.

Carey, J. (2015). Digital media and the transformation of space. In G. Einav (Ed.), The New World of Transitioned Media. The Economics of Information, Communication, and Entertainment (pp. 13-26). Cham: Springer.

Colier, N. (2016). The Power of Off: The Mindful Way to Stay Sane in a Virtual World. Boulder, CO: Sounds True.

Couldry, N., \& McCarthy, A. (2004). MediaSpace: Place, Scale and Culture in a Media Age. London and New York: Routledge. 
Croteau, D., \& Hoynes, W. (2019). Media/Society: Technology, Industries, Content, and Users. London: Sage.

Dalton, T. (2019). The Joy of Missing Out: Live More by Doing Less. Nashville, TN: Nelson Books.

Ehrenberg, A. (1998). La Fatigue d'être soi: Dépression et société. Paris: Odile Jacob.

Ellis, M. (2017). Digitox: How to Find a Healthy Balance for Your Family's Digital Diet. London: Culture Transform.

Enli, G. (2015). Mediated Authenticity: How Media Construct Reality. New York: Peter Lang.

Fang, I. (2015). From Alphabet to Internet: Media in Our Lives. New York: Routledge.

Formica, S. (2015). Digital Detox: 7 Steps to Find Your Inner Balance. n/a: Sandro Formica.

Goodin, T. (2018). Off: Your Digital Detox for a Better Life. New York: Abrams.

Honneth, A. (2004). Organized self-realization: Some paradoxes of individualization. European Journal of Social Theory, 7(4), 463-478.

Horkheimer, M., \& Adorno, T. (1997). The culture industry: Enlightenment as mass deception. In Dialectic of Enlightenment (pp. 120-167). London and New York: Verso.

Huffington, A. (2015). Thrive-The Third Metric to Redefining Success and Creating a Life of Well-Being, Wisdom, and Wonder. New York: Harmony.

Huxley, A. (2006 [1932]). Brave New World. New York, London, Toronto, Sydney: Harper Perennial.

Jorge, A. (2019). Social media, interrupted: Users recounting temporary disconnection on Instagram. Social Media + Society, 5(4), 2056305119881691. doi:10.1177/ 2056305119881691.

Karlsen, F., \& Syvertsen, T. (2016). You can't smell roses online: Intruding media and reverse domestication. Nordicom Review, 37. Retrieved from nordicom.gu.se/ sites/default/files/kapitel-pdf/10.1515_nor-2016-0021.pdf.

Krupp, E. (2014). Cellphone Addiction: Freedom from Social Media, Texting and Online Video. n/a: Erik Krupp.

Liang, K. D. (2015). Self-Improvement Books: A Genre Analysis. PhD dissertation, Victoria University of Wellington, Wellington, NZ.

Louv, R. (2008 [2005]). Last Child in the Woods: Saving Our Children from NatureDeficit Disorder. Chapel Hill, NC: Algonquin Books.

Louv, R. (2012). The Nature Principle: Reconnecting with Life in a Virtual Age. Chapel Hill, NC: Algonquin Books. 
Mander, J. (1978 [1977]). Four Arguments for the Elimination of Television. New York: Morrow.

McGee, M. (2005). Self-Help Inc: Makeover Culture in American Life: Oxford Scholarship Online: May 2012. DOI: 10.1093/acprof:oso/9780195171242.001.0001.

McLuhan, M. (1968 [1964]). Understanding Media: The Extensions of Man. London: Sphere Books.

Meyrowitz, J. (1985). No Sense of Place. New York and Oxford: Oxford University Press.

Meyrowitz, J. (1994). Medium theory. In Crowley, D., \& Mitchell, D. (Eds.), Communication Theory Today (pp. 50-77). Cambridge: Polity.

Neves, B. B., de Matos, J. M., Rente, R., \& Martins, S. L. (2015). The "nonaligned": Young people's narratives of rejection of social networking sites. YOUNG, 23(2), 116-135.

Orwell, G. (2008 [1949]). Nineteen Eighty-Four. London: Penguin.

Osbaldiston, N. (2012). Seeking Authenticity in Place, Culture and the Self. The Great Urban Escape. London: Palgrave McMillan.

Postman, N. (2005 [1985]). Amusing Ourselves to Death. London: Penguin.

Price, C. (2018). How to Break up with Your Phone: The 30-Day Plan to Take Back Your Life. London: The Orion Publishing Group.

Riesman, D. (1950). The Lonely Crowd. A Study of the Changing American Character. New Haven, CT: Yale University Press.

Scannell, P. (1996). Radio, Television and Modern Life. Oxford: Blackwell.

Schara, Z. (2017). An Analog Month: A Digital Detox in the Real World. Chicago: Zahara Schara.

Schoenebeck, S. Y. (2014). Giving up twitter for lent: How and why we take breaks from social media. Paper presented at the Proceedings of the SIGCHI Conference on Human Factors in Computing Systems.

Seamon, D., \& Sowers, J. (2008). Place and placelessness, Edward Relph. In Hubbard, P., Kitchen, R., \& Vallentine, G. (Eds.), Key Texts in Human Geography (pp. 43-51). London: SAGE.

Sennett, R. (1970). Uses of Disorder. Personal Identity and City Life. New Haven, CT: Yale University Press.

Shlain, T. (2019). 24/6: The Power of Unplugging One Day a Week. New York: Gallery Books.

Snow, B. (2017). Log Off: How to Stay Connected after Disconnecting. n/a: Blake Snow. Syvertsen, T. (2017). Media Resistance: Protest, Dislike, Abstention. Cham: Palgrave. Syvertsen, T. (2020). Digital Detox: The Politics of Disconnecting. Bingley: Emerald. 


\section{Rethinking Disconnection}

Syvertsen, T. \& Enli, G. (2019). Digital detox: Media resistance and the promise of authenticity. Convergence, Online first, 2019.

Talks, M. (2013). A to $Z$ of Digital Detoxing: A Practical Family Guide. n.a.: Martin Talks.

Tennant, K. (2012). Unfriend Yourself: Three Days to Discern, Detox and Decide About Social Media. Chicago: Moody.

Turkle, S. (2011). Alone Together: Why We Expect More from Technology and Less From Each Other. New York: Basic Books.

Turkle, S. (2015). Reclaiming Conversation. The Power of Talk in the Digital Age. New York: Penguin.

Zahariades, D. (2016). Digital Detox: Unplug to Reclaim Your Life. n/a: Damon Zahariades. 